\title{
The Effects of Anxiety and Preparation on Performance in Technical Interviews for HBCU Computer Science Majors
}

\author{
Phillip Hall, Jr. \\ Clemson University \\ School of Computing \\ Clemson, SC, USA \\ pwhall@g.clemson.edu
}

\author{
Kinnis Gosha \\ Morehouse College \\ Department of Computer Science \\ Atlanta, GA, USA \\ kinnis.gosha@morehouse.edu
}

\begin{abstract}
Interview anxiety affects us all and research suggests that it can have a negative impact on interview performance. For that reason, a better understanding of how interview anxiety is affecting underrepresented minorities in computing should be a goal of academic institutions and companies who plan to hire these students. Technical computing interviews often require more than just knowing how to code, and students are not always aware of this. The current study investigates interview anxiety, interview performance among African-American students at Historically Black Institutions and the tools they use to prepare for interviews. Findings suggest that interview performance decreases as interview anxiety increases, supporting past research. Also, results suggest that experience going through interviews have a positive impact on interview anxiety. The major contributions of this work include: further understanding of the research literature for interview anxiety in relation to African American students in computing; incite in how this group of students prepare for interviews.
\end{abstract}

\section{CCS CONCEPTS}

- Social and professional topics $\rightarrow$ Employment issues; Computing industry; Race and ethnicity;

\section{KEYWORDS}

interview anxiety, technical interview, careers, HBCUs

ACM Reference Format:

Phillip Hall, Jr. and Kinnis Gosha. 2018. The Effects of Anxiety and Preparation on Performance in Technical Interviews for HBCU Computer Science Majors. In SIGMIS-CPR '18: 2018 Computers and People Research Conference, fune 18-20, 2018, Buffalo-Niagara Falls, NY, USA. ACM, New York, NY, USA, 6 pages. https://doi.org/10.1145/3209626.3209707

\section{INTRODUCTION}

Preparing for a technical interview as a computer science student or graduate can be a stressful time. By the year 2020, software engineering jobs are expected to increase by $30 \%$ [28]. Recent diversity numbers released by bag tech companies like Google, Apple and

Permission to make digital or hard copies of all or part of this work for personal or classroom use is granted without fee provided that copies are not made or distributed for profit or commercial advantage and that copies bear this notice and the full citation on the first page. Copyrights for components of this work owned by others than ACM must be honored. Abstracting with credit is permitted. To copy otherwise, or republish, to post on servers or to redistribute to lists, requires prior specific permission and/or a fee. Request permissions from permissions@acm.org.

SIGMIS-CPR '18, June 18-20, 2018, Buffalo-Niagara Falls, NY, USA

(c) 2018 Association for Computing Machinery.

ACM ISBN 978-1-4503-5768-5/18/06 . \$15.00

https://doi.org/10.1145/3209626.3209707
Facebook show a tremendous lack of African-American representation $[2,5,18]$. Not surprisingly, Google and Apple are two of the top three choices of where computer scientist graduates want to work according to a study by Global research and advisory firm Universum where 81,102 students from 359 US universities were surveyed [11].Less than $2 \%$ of technical roles are filled by African Americans at these top companies. Several top tech companies like Google, Facebook and Apple have developed relationships with HBCUs $[13,17,19]$ in order to identify and interview candidates for entry level, software engineering positions however there has been no significant change in the number of African American technical workforce at those companies. The technical interview is seen as the major barrier for most students who wish to gain entry level software engineering positions at the top tech companies [22], thus how computer science students at HBCUs prepare for and perform on these interviews must be investigated in order to know why the diversity numbers at these top tech firms have not shown any significant growth in order to investigate this, two research questions will be addressed.

RQ1: How are CS students from Historically Black Institutions preparing for interviews?

The lack of African Americans in technical roles at top tech companies may come from one or combination of three things: lack of students that apply for entry level tech positions, lower performance on these interview by those who do apply or interest in applying altogether. In this paper, we will only investigate the option that students don't perform as well as their majority peers. The rationale for choosing this option is based on feedback provided to multiple CS faculty members at diversity events hosted by The United Negro College Fund and sponsored by these top tech companies: Ebay, Google, Amazon, Twitter, Facebook, NetApp, Uber [3]. Performance on the technical interview can be a product of the concepts that the students know and their problem solving ability, however other factors may contribute to the outcome of interview as well. One of those is anxiety.

RQ2: Does interview anxiety impact performance in technical interviews?

Technical interviews require more than being able to code, interviewees are rated on their problem solving, people, team working and critical thinking skills [15, 22]. All of these skills require cognitive functions that are influenced by stress and anxiety, specifically interview anxiety. Interview anxiety refers to nerves or jitters that 
individuals experience prior to and during the job interview. As a result, many candidates dread job interviews and experience negative thoughts about their performance in the days leading up to it [20]. Previous research by [30] suggests that anxious individuals are less likely to be hired in both simulated and real interview situations. As CS graduates leave their institutions behind they are expected to know how to deal with interview anxiety, what to expect on an interview, and to feel as if their institution prepared them adequately for interviewing.

The intent of the present investigation is to provide descriptive results to better understand the experience of interview anxiety among students at Historically Black Institutions in Computer Science majors by investigating the relationship between interview anxiety, interview performance and interviewing experience. To investigate this a few predictions have been made. Consistent with past research, first we hypothesized that interview anxiety and interview performance will be negatively correlated. Second, we predict that interviewing experience and interview anxiety will be negatively correlated. Thus, as interview experience increases, interviews anxiety levels on new interviews will decrease.

The following paper will present research on interview anxiety and its effects on performance, college students and how they prepare for technical interview and the representation of minorities in big tech. After that the study method and results will be discussed followed by a conclusion and future work section.

\section{RELATED WORK}

\subsection{Interview Anxiety}

Studies of anxiety and its negative effects on human performance are numerous and psychologists have theorized that moderate levels of anxiety are ideal [30]. Surprisingly, there are few studies of anxiety in employment interviewing contexts, where performance is a critical determinant in hiring decisions and anxiety levels are likely to be high. One study [14] says that most job applicants experience interview anxiety. Another study [26] found that interview anxiety negatively impacted interview self-efficacy, suggesting that one consequence of interview anxiety is reduced confidence that one can do well in an interview. Furthermore [14] found that individuals who are anxious in public-speaking situations and job interviews experience more verbal difficulties, and [8] discovered that anxiety has an effect on body language, communication, eye contact, voice levels, and projected confidence. The previously mentioned points are all hiring determinants [21]. Although interview specific anxiety may be related to long-term tendencies to be anxious (e.g., neuroticism), there is reason to believe that interview anxiety is a separate and specific state. For instance, having limited job prospects could increase interview anxiety, even for interviewees who would not normally be anxious during an interview, while having several offers in hand could decrease anxiety. Other cognitive research suggests that the ability to retrieve information from long-term memory tends to be impaired under conditions of stress [27]. For colleges, having a holistic understanding of interview anxiety can help with preparing students for interviews [8].

\subsection{Preparing for Interviews}

2.2.1 Interview Training in the Curriculum.

At Stanford University in California, CS students can register for a class entitled Problem-Solving for the CS Technical Interview. The course prepares students to interview for software engineering and related internships and full-time positions in industry [27]. The course requires students to synthesize information they have learned across different courses in the CS major. Emphasis is placed on the oral and combination written-oral modes of communication common in coding interviews, but which are an unfamiliar setting for problem solving for many students. According to [8], anxiety reduction therapy can be successfully embedded in classroom experiences. Stanford's efforts should cause a decrease in interview anxiety for students who complete the course. Laboratory work associated with an anxiety producing stimulus will reduce that performance anxiety dramatically without requiring additional"therapy time[8]." Other research conducted by [16, 23] suggest that best practices in interview training include variations of instructions and models of target skills, followed by practicing those skills and receiving feedback. This means that students do best in interviews when they are given a variety of "target skills" to practice and given feedback on their practice. According to the [1] 67\% ( $N=699)$ of employers say that recent graduates need to improve their interview performance, suggesting that there is a need to improve interview training at academic institutions

Since high levels of anxiety are associated with inferior performance in many settings, it seems reasonable that instructors include employment interviewing and interview anxiety reduction mechanisms in the curriculum. Unless a student has experienced a technical interview, knows someone who has, or done their own research, they have no idea what to expect.

\subsubsection{Online Interview Training.}

With the popularity and demand for code rapidly growing, more ways for individuals to learn how to code, practice code and prepare for coding interviews are being introduced. There are several websites that offer code interview training. Leetcode.com, InterviewCake.com, InterviewBit.com offer practice on historically asked coding interview questions and claim to help interviewees land offers at companies like Google, Facebook and more. InterviewCake.com guarantees its paid users a job or their money back. InterviewCake.com offers free access to some of the site content but users have to pay a one-time fee of $\$ 599$ to get full access to all courses on the site. Pramp.com is a site that believes its users should not prepare for interviews alone and gives them the opportunity to practice with real people. Using video conferencing, users can train with peers and professionals online to improve programming interview skills. Other websites like Coursera.com and Udacity.com offer courses that users take to learn how to code or to improve their coding skills, although these websites are not targeted toward interview training they do offer code practice outside of a classroom setting.

\subsubsection{Textbook Training.}

At the time of this writing, Cracking the Coding Interview: 189 Programming Questions and Solutions 6th Edition was the bestselling 
book in the Data Structure and Algorithms section on Amazon.com, the largest book retailer in the world [9]. Another title by Adnan, Tsung-Hsien and Amit is Elements of Programming Interviews: The Insiders' Guide [6].

\subsection{Resources at Historically Black Institutions}

Historically Black Institutions have always lagged behind funding for predominantly White land-grant universities for over 100 years, and it is only getting worse [4]. This impacts the amount of quality professors, as well as the quality of learning resources institutions can provide for their students. This should concern CS departments at Historically Black Institutions, students are expected to not only be prepared to perform on the job but also to ace the interview.

Preparation is very important for a technical CS interview. [10] suggests that Black and Hispanic students are unaware of how to prepare for an interview for a major tech company. The article states that Black and Hispanic students are not aware of what the technical interview consists of therefore do not know how to prepare. It is also important to point out that very few CS professors at a Historically Black Institutions have experienced a technical interview at a major tech company. Ten professors (including the authors of this manuscript) representing 10 different Historically Black Institutions went through a software engineering interview at Google while participating in a six-week long faculty workshop. Researchers held interviews with three professors who were part of that group; they gave feedback on their experiences. For most of the professors it was their first time experiencing an industry style technical computing interview. One professor of over 10 years stated that during the interview they felt as if they were taking a final exam in college all over again, "I was extremely nervous" stated one professor. Another professor of 15 years also mentioned being very nervous. If professors have not experienced these types of interviews or are not aware of what they consist of; how can they be expected prepare their students for these interviews?

\subsection{Underrepresented Minority Presence in Tech Industry}

Currently the tech industry is experiencing an issue with diversity and lags when it comes to hiring minorities [29]. Many companies are currently going great lengths to fix this issue, but numbers continue to stay stagnant even when minorities are getting CS degrees [29]. Google recently pledged \$265 million, while Apple and Microsoft pledged over $\$ 50$ million towards increasing diversity numbers $[5,17]$. In the summer of 2017, Google launched two major programs, "Howard West" and "HBCU Faculty in Residence". Howard West was a program that brought 25-30 juniors and faculty from Howard's CS program to Google's headquarters in Silicon Valley for 12 weeks to take courses co-taught by Google software engineers [19]. HBCU Faculty in Residence was a six week program (attended by by both authors of the paper) where $30 \mathrm{HBCU}$ CS faculty worked at Google as interns, with the job of learning about the culture of Google as well as developing curriculum in collaboration with Google engineers based on what they learned. Another Google program, Google in Residence, is a program where a Google software engineer moves to the city where an HBCU is located and teaches a freshman level CS course [17]. In 2015, Apple made a $\$ 40$ million dollar multi-year commitment, the largest and most comprehensive corporate investment ever given exclusively for students and faculty of four-year HBCUs [24].

Given the diversity numbers, one has to assume one of the following: interview performance must not be adequate, students are not applying for these jobs, or students are applying but not landing interviews. [7] says that minority college students often report higher rates of anxiety than their white peers, suggesting that white CS students experience less interview anxiety, which may result in better performance in interviews than their underrepresented peers. When discussing interview anxiety amongst this population, imposter syndrome must be addressed. Research has suggested that underrepresented minorities do exhibit higher levels of imposter syndrome than their white counterparts [12]. Those who suffer from impostor syndrome cannot grasp or believe in their successes, even if they are high achieving, leading them to feel like frauds. In some cases impostor syndrome can degrade mental health [12]. From all of this we can assume that interview anxiety among recent college graduates and students could affect diversity numbers in the computing industry.

\section{EXPERIMENTAL DESIGN}

A quantitative research study was conducted in order to answer the following two research questions,"How are CS students from Historically Black Institutions preparing for interviews?" and "Does interview anxiety impact performance in technical interviews?". Undergraduate computer science majors were recruited from a Historically Black Institution in southeastern United States to participate in the study. Students who were upperclassmen (junior and seniors) were preferred to participate in the study since they would have more experience participating in technical interviews. Additionally, students were not required to have had participated in a technical interview in order to participate in the study since they would be able to answer some questions about what they know in order to study for a technical interview. A convenience sample was chosen to give the largest number of responses with the small number of students available. The survey was administered to the participants electronically. The students who participated where all enrolled in a 400 level required CS course. Students were asked to complete a survey in exchange for a movie style box of candy.

\subsection{Procedure}

The survey asked questions about experiences with technical interviews. Participants were asked to answer questions for each technical interview they experienced. The following questions were used in analysis: How many technical computing interviews have you been on?, How many hours per week do you spend preparing for interviews? How familiar are you with the following interview prepping resources? The first question recorded the amount of interviews each participant had been on, this question was later used in the data analysis to split the participants into two groups. The second question was asked in intervals: None, 1-5 hours a week, 6-10 hours a week, 11-15 hours a week, more than 16 hours. This allowed researchers to gather data participant practice habits. The 
third was a likert scale question with five options: Extremely $\mathrm{Fa}$ miliar, Very Familiar, Moderately Familiar, Slightly Familiar, Not Familiar At All, that recorded participant familiarity with the following interview practice tools: Cracking the Coding Interview: 189 Programming Questions and Solutions Book, InterviewBit.com, InterviewCake.com, CourseEra.com, Udacity.com, Pramp.com and Mock Interviews. For each interview, students completed a State Trait Anxiety Inventory (STAI-Y) Scale. The STAI-Y is the most widely used self-reported measure of anxiety, developed in 1977 by Charles Spielberger.

\subsection{Measures}

Students were asked to complete a STAI-Y scale for every interview. An interview anxiety score was generated from the scale values. Students rated their performance for each interview. The students were also asked to report how many technical interviews they had experienced. Additionally, student were also asked about the number of hours they practice/prepare for technical interviews and what tools they used to prepare for those interviews.

\section{RESULTS}

Nine (9) juniors and 15 seniors were asked how familiar they were with the seven interview training tools listed previously, see Table 1.

There were five juniors and seven seniors, the average age was 21 , with the oldest being 23 , the youngest being 20 . The amount of interviews per participant varied with $2(\mathrm{~N}=3)$ being the lowest and $6(\mathrm{~N}=1)$ being the most. Participants were put into two groups based off interview experience:

Group 1: $<=3$ interviews $(\mathrm{N}=7)$

Group 2: $>3$ interviews $(\mathrm{N}=5)$

Two independent sample t-tests were conducted to test for significance between groups for the first and last interview, used as two separate conditions. Interview anxiety means were calculated using interview anxiety levels from each condition. There was no

Table 1: Familiarity with Coding Interview Resources 1-Extremely familiar, 2-Very familiar, 3-Moderately familiar, 4-Slightly familiar, 5-Not familiar at all

\begin{tabular}{|c|c|c|c|c|c|}
\hline $\begin{array}{l}\text { How familiar are you } \\
\text { with the following } \\
\text { interview training } \\
\text { resources? }\end{array}$ & 1 & 2 & 3 & 4 & 5 \\
\hline InterviewBit.com & $4 \%$ & $0 \%$ & $17 \%$ & $17 \%$ & $63 \%$ \\
\hline $\begin{array}{c}\text { Cracking the Coding } \\
\text { Interview: 189 } \\
\begin{array}{c}\text { Programming Questions } \\
\text { and Solutions Book }\end{array}\end{array}$ & $25 \%$ & $33 \%$ & $13 \%$ & $21 \%$ & $8 \%$ \\
\hline InterviewCake.com & $0 \%$ & $4 \%$ & $21 \%$ & $8 \%$ & $58 \%$ \\
\hline CourseEra.com & $8 \%$ & $4 \%$ & $21 \%$ & $8 \%$ & $25 \%$ \\
\hline Udacity.com & $21 \%$ & $21 \%$ & $25 \%$ & $8 \%$ & $25 \%$ \\
\hline Pramp.com & $0 \%$ & $4 \%$ & $12 \%$ & $8 \%$ & $75 \%$ \\
\hline Mock Interviews & $46 \%$ & $8 \%$ & $25 \%$ & $8 \%$ & $13 \%$ \\
\hline
\end{tabular}

significant difference between group anxiety levels in their first and last interviews.

\subsection{Interview Anxiety effects on Interview Performance}

For both groups, the relationship between interview anxiety and interview performance during their first and last interviews gave negative correlations $(\mathrm{r}=-.38, \mathrm{r}=-.42)$. As anxiety went up performance went down, this supports past research on interview anxiety effects on performance.

\subsection{Interview Experience effect on Interview Anxiety}

A within group paired sample t-test revealed that students in Group 1 interview anxiety level in the last interview was significantly higher compared to the first interview $(\mathrm{p}=.04)$, while Group 2 showed no significance $(\mathrm{p}=.4)$.

Due to this finding, a one-way ANOVA was conducted for Group 1 to compare the effect of interview experience on interview anxiety for their first interview and their final interview. There was a significant effect of interview experience on interview anxiety at the $\mathrm{p}<.05$ level for the two conditions $[\mathrm{F}(1,12)=4.8, \mathrm{p}=.048]$.

All participants anxiety levels went up on their second and/or third interview. But after four interviews participant interview anxiety level remained normal or decreased. This could suggest that because students in Group 2 had four or more interviews, their anxiety level on their last interview was not significantly higher than it was for participants in Group 1 on their last interview.

\subsection{Interview Preparedness}

Since every participant experienced a minimum of 2 interviews researchers decided to use the data reported for interviews $1 \& 2$ for the following analysis.

When preparing for interviews; students reported that they use mock interviews $58 \%$ of the time, online tools leetcode.com or hackeron.com $16 \%$ of the time, and $12 \%$ of the time students used

the Cracking the Coding Interview book. Table 3 shows the complete analysis. Based on this data we can assume that students prefer mock interviews, over other interview training tools, and based on past research mock interviews have a positive impact on interview anxiety.

When asked how many hours were spent per week preparing for interviews, $50 \%$ spend between 1 and 5 hours, while $25 \%$ stated they do not practice at all, See Table 2 for full breakdown.

Table 2: Time Preparing for Interviews

\begin{tabular}{|c|c|c|}
\hline \multicolumn{3}{|c|}{$\begin{array}{c}\text { How many hours do you spend a week } \\
\text { preparing for interviews? }\end{array}$} \\
\hline 1-5 hours & $\mathbf{6 - 1 0}$ hours & None \\
\hline $50 \%$ & $25 \%$ & $25 \%$ \\
\hline
\end{tabular}


Table 3: Methods for Preparing for Interviews

\begin{tabular}{|c|c|}
\hline \multicolumn{2}{|c|}{ What tools did you use to prepare for the interview? } \\
\hline Mock Interviews & $58.3 \%$ \\
\hline Online Tools & $16.7 \%$ \\
\hline $\begin{array}{c}\text { Cracking The Code } \\
\text { Interview Book }\end{array}$ & $12.5 \%$ \\
\hline Did Not Prepare & $12.5 \%$ \\
\hline
\end{tabular}

\section{CONCLUSIONS}

\subsection{Discussion}

The current study provided empirical support for our first hypothesis that an individual's interview performance will be negatively impacted as their anxiety increases, supporting previous research but offering new insight for this particular demographic. The current study also provides support for our second hypothesis, there was a significant effect on interview anxiety due to interview experience. Students who had more experience going on interviews were less likely to experience higher anxiety. This finding suggests that by going through more interviews students can improve their interview anxiety which should improve their performance. As mentioned earlier, underrepresented minority students are less likely to be aware of how to prepare for technical interviews, and many may not even go through an interview due imposter syndrome. But accordingly, to the concurrent data, experiencing as many interviews as possible could be the trick to performing well. This makes sense, but students who suffer from imposter syndrome may also feel like they don't have many chances to fail an interview at a prestigious company. Therefore, going through an interview and not getting the job, translates to many as never getting a job with that company. When the reality is that many of the employees at these prestigious companies failed the interview process more than once before getting the job [25]. Interview anxiety deserves the attention of universities and companies, in order to understand and be aware during interviews with individuals from certain demographics.

All participants stated they either reviewed old classwork, used an online tool, used the cracking the code book, used mock interviews, or nothing at all to prepare for the interviews they listed. Mock interviews were the most utilized interview preparation intervention across all participants. Past research suggests that mock interviews could be the best way to combat interview anxiety, but a downside to mock interviews is that they require time coordinating for at least two individuals. Time that is not always available or easy to come by for a college student, and in academic environments where resources are already limited, providing access to unlimited mock interviews is not realistic. Students should have unlimited access to interview training tools that incorporate, as best as possible, all the sensations experienced in a mock interview.

As time progresses, we believe more training tools will become available. Ideally, these tools will incorporate some mechanism to allow their users to simulate the technical interview process in order to mitigate the negative impacts of interview anxiety. If CS faculty wants to adequately prepare their students for an entry level software engineering position at a major tech company, curriculum should include activities or coursework to help students prepare for technical interviews.

InterviewCake.com guarantees a job or your money back, but in this group of students, majority of them never heard of the website.

\subsection{Limitations \& Future Work}

Limitations in the study include a small sample size of participants and the lack of students from multiple HBCUs participating in the study. Also, gender was not asked nor was the career goals of each participant asked in the survey instrument. Future research should incorporate students from multiple HBCUs as well as students from non-HBCU institutions to serve as a control group. Also, the relation between how students prepare for interviews and interview performance should be investigated. Will certain tools, if available, cause students to perform better or worse? Also, research should be done creating and testing new tools that would give students an "authentic" interview experience, similar to mock interviews, but that do not require as much time sacrifice. Data on the amount of job offers, or interviews, participants had at the time of going through an interview was not included in this paper. Future work on this data could present some correlations between interview anxiety, or performance, and the amount of offers, or interviews, on an individual's schedule.

\section{ACKNOWLEDGEMENTS}

Funding for this research was made possible by the National Science Foundation, Division Of Human Resource Development (Award \#1547793).

\section{REFERENCES}

[1] 2012. The Role of Higher Education in Career Development: Employer Preparations. The Chronicle of Higher Education. http://www.chronicle.com/items/biz/pdf/ Employers\%20Survey.pdf

[2] 2017. Facebook Diversity Update: Building a more diverse, inclusive workforce. (2017). https://fbnewsroomus.files.wordpress.com/2017/08/fb_diversity_2017_ final.pdf

[3] 2017. HBCU ICE 2017 UNCF HBCU Innovation Summit. (2017). http://www. hbcuinnovation.org/

[4] 2017. A Looming Crisis for HBCUs? An Analysis of Funding Sources for Land Grant Universities. National Education Association. http://www.nea.org/assets/docs/ NEA\%20CGPS\%20Research\%20HBCU\%20Brief\%202.pdf

[5] Apple. 2018. Inclusion \& Diversity. (2018). https://www.apple.com/diversity/

[6] Adnan Aziz, Amit Prakash, and Tsung-Hsien Lee. 2012. Elements of programming interviews.

[7] Jeremy Bauer-Wolf. 2017. Feeling Like Imposters. (2017). https://www.insidehighered.com/news/2017/04/06/ study-shows-impostor-syndromes-effect-minority-students-mental-health.

[8] Ralph R. Behnke and Chris R. Sawyer. 1999. Milestones of anticipatory public speaking anxiety. Communication Education 48, 2 (1999), 165-172. https://doi. org $/ 10.1080 / 03634529909379164$

[9] Jeff Bercovici. 2014. Amazon Vs. Book Publishers, By the Number. (2014). https://www.forbes.com/sites/jeffbercovici/2014/02/10/ amazon-vs-book-publishers-by-the-numbers/\#6d2e62934ef9.

[10] Quoctrung Bui and Claire Cain Miller. 2016. Why Tech Degrees Are Not Putting More Blacks and Hispanics Into Tech Jobs. (2016). https://www.nytimes.com/2016/02/26/upshot/ dont-blame-recruiting-pipeline-for-lack-of-diversity-in-tech.html

[11] A Cain. 2017. 15 places where computer science majors dream of working. (2017). http://www.businessinsider.com/ dream-companies-and-organizations-for-computer-science-students-2017-5.

[12] Kevin Cokley, Leann Smith, Donte Bernard, Ashley Hurst, Stacey Jackson, Steven Stone, Olufunke Awosogba, Chastity Saucer, Marlon Bailey, and Davia Roberts. 
2017. Impostor feelings as a moderator and mediator of the relationship between perceived discrimination and mental health among racial/ethnic minority college students. Journal of Counseling Psychology 64, 2 (2017), 141-154. https://doi.org $10.1037 / \mathrm{cou} 0000198$

[13] Emily DeRuy. 2015. Apple Pledges $\$ 40$ Million to HBCUs in Scholarships and Support. (2015). https://www.theatlantic.com/politics/archive/2015/09/ apple-pledges-40-million-to-hbcus-in-scholarships-and-support/432726/

[14] Amanda R. Feiler and Deborah M. Powell. 2013. Interview anxiety across the sexes: Support for the sex-linked anxiety coping theory. Personality and Individual Differences 54, 1 (2013), 12-17. https://doi.org/10.1016/j.paid.2012.07.030

[15] George Forman. 2003. An extensive empirical study of feature selection metric for text classification. Journal of machine learning research 3, Mar (2003), 12891305.

[16] John P. Galassi and Merna Dee Galassi. 1978. Preparing Individuals for job Interviews: Suggestions From More Than 60 Years of Research. The Personnel and Guidance fournal 57, 4 (1978), 188-192. https://doi.org/10.1002/j.2164-4918. 1978.tb05142.x

[17] Google. 2017. Hiring diverse Googlers: We're expanding the ways we look for Googlers and creating additional pathways to Google. (2017). https://www. google.com/diversity/hiring.html

[18] Google. 2018. Our Workplace - Google Diversity. (2018). https://diversity.google/ commitments/

[19] Jessica Guynn. 2017. Google opens Howard University West to train black coders. (2017). https://www.usatoday.com/story/tech/news/2017/03/23/ howard-university-google/99518020/

[20] Richard G. Heimberg, Kevin E. Keller, and Theresa A. Peca-Baker. 1986. Cognitive assessment of social-evaluative anxiety in the job interview: Job Interview SelfStatement Schedule. Fournal of Counseling Psychology 33, 2 (1986), 190-195. https://doi.org/10.1037//0022-0167.33.2.190
[21] Allen I. Huffcutt, Chad H. Van Iddekinge, and Philip L. Roth. 2011. Understanding applicant behavior in employment interviews: A theoretical model of interviewee performance. Human Resource Management Review (2011). https://doi.org/10. 1016/j.hrmr.2011.05.003

[22] Gayle Laakmann McDowell. 2015. Cracking the coding interview: 189 Programming Questions and Solutions (6 ed.). CareerCup.

[23] Van M. Latham. 1987. Interviewee Training: A Review of Some Empirical Literature. Fournal of Career Development 14, 2 (1987), 96-107. https://doi.org/10.1177/ 089484538701400204

[24] Samara Lynn. 2015. Apple Rewards 30 HBCU Students Scholarships in \$40 Million Dollar Diversity Effort. (2015). http://www.blackenterprise.com/technology/ apple-awards-30-hbcu-students-scholarships-in-40-million-diversity-effort/

[25] Shannon Shaper. 2017. How many interviews does it take to hire a Googler? (2017). https://rework.withgoogle.com/blog/google-rule-of-four/

[26] Stuart A. Tross and Todd J. Maurer. 2008. The effect of coaching interviewees on subsequent interview performance in structured experience-based interviews. Journal of Occupational and Organizational Psychology 81, 4 (2008), 589-605. https://doi.org/10.1348/096317907x248653

[27] Standford University. 2017. CS9: Problem-Solving for the CS Technical Interview. (2017). http://web.stanford.edu/class/cs9/

[28] U.S. Bureau of Labor Statistics. 2015. Computer and Information Technology Occupations. (2015). https://www.bls.gov/ooh/ computer-and-information-technology/home.htm

[29] Elizabeth Weise and Jessica Guynn. 2014. Tech jobs: Minorities have degrees, but don't get hired. (2014). https://www.usatoday.com/story/tech/2014/10/12/ silicon-valley-diversity-tech-hiring-computer-science-graduates-african-american-hispanic/ 14684211/

[30] Melissa J. Young, Ralph R. Behnke, and Yvonne M. Mann. 2004. Anxiety patterns in employment interviews. Communication Reports 17, 1 (2004), 49-57. https: //doi.org/10.1080/08934210409389373 